\title{
PERBEDAAN PENGARUH LATIHAN PLYOMETRIC DAN LATIHAN CIRCUIT TERHADAP JUMPING SMASH PADA ATLET BULUTANGKIS PB INDEPENDENT KARANGANYAR TAHUN 2020

\author{
Bonita Mahendrajati ${ }^{1}$, Slamet Sudarsono ${ }^{2}$
}

\begin{abstract}
ABSTRAK
Tujuan dari penelitian ini adalah untuk mengetahui : (1) Untuk mengetahui perbedaan pengaruh latihan plyometric dan latihan circuit terhadap peningkatan kemampuan jumping smash bulutangkis pada atlet PB Independent Karanganyar. (2) Untuk mengetahui perbedaan pengaruh yang lebih baik antara latihan plyometric dan latihan circuit terhadap peningkatan kemampuan jumping smash bulutangkis pada atlet PB Independent Karanganyar.

Penelitian ini menggunakan metode eksperimen dengan desain "two groups pretest-post-test design". Populasi dalam penelitian ini adalah atlet PB. Independen Karanganyar yang berjumlah 20 orang. Teknik sampling dalam penelitian ini menggunakan total sampling. Instrumen dalam penelitian ini menggunakan tes kemampuan Ketepatan Jumping smash yang dikemukakan oleh PBSI. Teknik analisis data menggunakan uji reliabilitas, uji normalitas dan uji homogenitas, sedangkan uji hipotesis menggunakan uji $t$.

Simpulan bahwa: (1) Ada perbedaan pengaruh yang signifikan latihan plyometric dan latihan circuit terhadap peningkatan kemampuan jumping smash bulutangkis pada atlet PB Independent Karanganyar. Peningkatan persentase kelompok latihan plyometric sebesar 4\% dan Peningkatan persentase kelompok latihan circuit sebesar 2\%. (2) Latihan plyometric memberikan pengaruh yang lebih signifikan daripada latihan circuit terhadap peningkatan ketepatan jumping smash bulutangkis pada atlet PB Independent Karanganyar, dengan selisih rata-rata kenaikan nilai sebesar 0,700.
\end{abstract}

\section{Kata kunci : Latihan plyometric, Latihan circuit, Ketepatan jumping smash}

\section{PENDAHULUAN}

Bulutangkis merupakan salah satu olahraga terkenal di dunia. Bulutangkis dapat menenembus di kalangan masyarakat yang mempunyai batasan etnis, agama, dan budaya. Olahraga ini menarik minat berbagai kelompok usia, berbagai tingkat keterampilan, dan dimainkan oleh pria maupun wanita di dalam atau di luar ruangan untuk rekreasi juga sebagai ajang persaingan. 
Hampir di setiap pelosok desa sampai dengan kota kabupaten, banyak dijumpai lapangan bulu tangkis. Namun sayangnya secara umum berdasarkan pengamatan, belum kelihatan adanya pembinaan yang benar sehingga kualitas dalam melakukan jumping smash bulu tangkis masih belum kelihatan baik atau dengan lain perkataan, para penduduk dalam melakukan jumping smash belum menggunakan teknik-teknik yang benar, sehingga hasilnya tidak optimal.

Salah satunya di PB. Independent Karanganyar, kemampuan atlet untuk melakukan jumping smash masih kurang. Serta terdapat beberapa atlet yang kurang berhasil dalam melakukan jumping smash bulutangkis pada atlet bulutangkis PB Independen Karanganyar. Padahal pukulan ini sangat penting dalam suatu pertandingan. Pada saat bermain, sebagian besar hasil ketepatan jumping smash yang dilakukan oleh atlet terlalu melebar ke kanan dan ke kiri, sehingga pukulan jumping smash yang seharusnya menghasilkan poin untuk diri sendiri, justru malah lebih banyak menghasilkan poin untuk lawan.

Oleh karena itu, diperlukan suatu cara yang tepat untuk melatihkan kemampuan ketepatan jumping smash ini. Untuk memperbaiki permasalahan yang ditemukan latihan jumping smash antara lain menggunakan metode latihan plyometric dan latihan cirkuit dipilih sebagai metode latihan bulutangkis, mengingat latihan plyometic dan latihan circuit belum pernah dipergunakan untuk melatih kemampuan jumping smash pada atlet bulutangkis PB Independen Karanganyar.

\section{LANDASAN TEORI}

\section{Bulu Tangkis}

Bulutangkis merupakan salah satu olahraga terkenal di dunia. Bulutangkis dapat menenembus di kalangan masyarakat yang mempunyai batasan etnis, agama, dan budaya. Olahraga ini menarik minat berbagai kelompok usia, berbagai tingkat keterampilan, dan dimainkan oleh pria maupun wanita di dalam atau di luar ruangan untuk rekreasi juga sebagai ajang persaingan. 
Bulutangkis adalah permainan yang dimainkan satu lawan satu (single) dan dua lawan dua (double) dengan peraturan yang sudah ditentukan cara memainkannya dengan memukul shuttlecock melewati atas net menggunakan raket. Bulutangkis merupakan cabang olahraga yang dimainkan dengan menggunakan raket sebagai alat pemukul, dan shuttlecock dengan teknik pukulan. Lapangan permainan berbentuk segiempat dan dibatasi oleh net atau jarring yang berfungsi untuk memisahkan daerah permainan lawan yang saling berhadapan.

Tohar (1992: 67) mengemukakan "macam-macam teknik pukulan bulutangkis yang harus dikuasai adalah pukulan servis, pukulan lob atau clear, pukulan dropshot, pukulan smash, pukulan drive atau mendatar, dan pengembalian servis atau return service".

\section{Latihan Plyometric}

"Plyometric berasal dari kata "plyethyein" (Yunani) yang berarti untuk meningkatkan, atau dapat pula diartikan dari kata "plio" dan "metric" yang artinya more and measure, respectively yang artinya penguluran" (Radcliffe and Farentinos, 1985: 3). Menurut Chu (1992) "plyometric adalah suatu metode latihan yang menitikberatkan gerakan-gerakan dengan kecepatan tinggi, plyometric melatih untuk mengaplikasikan kecepatan pada kekuatan”. Bentuk latihan plyometric yang akan digunakan dalam penelitian ini adalah box drills, frog jumps, dan standing jump.

\section{Latihan Circuit}

Menurut Muhajir (2007: 58), “circuit training adalah urutan latihan dengan satu macam kegiatan di setiap pos antara 4-12 pos. Olahragawan bebas untuk memulai latihan dari mana saja. Untuk itu dalam menyusun urutan item latihan diusahakan sasaran otot yang ditingkatkan berseling". Artinya otot yang dikenai beban latihan berganti-ganti pada setiap item latihan. Beberapa bentuk item latihan terdiri dari push up, sit up, back up, squat trust, skipping. 


\section{Jumping Smash Bulutangkis}

Jumping smash merupakan suatu pukulan yang keras dan curam sepenuh tenaga mengarah ke bidang lapangan pihak lawan dengan meloncat. Tujuan utamanya adalan mematikan lawan. Faktor utama yang mempengaruhi smash adalah shuttlecock yang melambung tinggi diatas kepala yang posisinya mendukung untuk melakukan pukulan jumping smash dengan maksimal hingga dapat membuat lawan susah untuk mengembalikan ataupun dapat membuat lawan tidak dapat mengembalikan shuttlecock.

\section{METODE PENELITIAN}

Metode yang akan digunakan dalam penelitian ini adalah metode eksperimen. Tujuan penelitian eksperimen adalah meneliti ada tidaknya hubungan sebab - akibat serta besarnya hubungan tersebut tersebut dengan cara memberikan perlakuan terhadap kelompok eksperimen yang hasilnya dibandingkan dengan hasil kelompok yang diberikan perlakuan yang berbeda. Penelitian ini mempunyai dua kelempok untuk diteliti, sehingga dikategorikan kedalam penelitian perbandingan (comparative experiment). Karena akan membandingkan hasil latihan plyometric dengan latihan circuit terhadap ketepatan pukulan jumping smash. Adapun desain penelitian sebagai berikut:

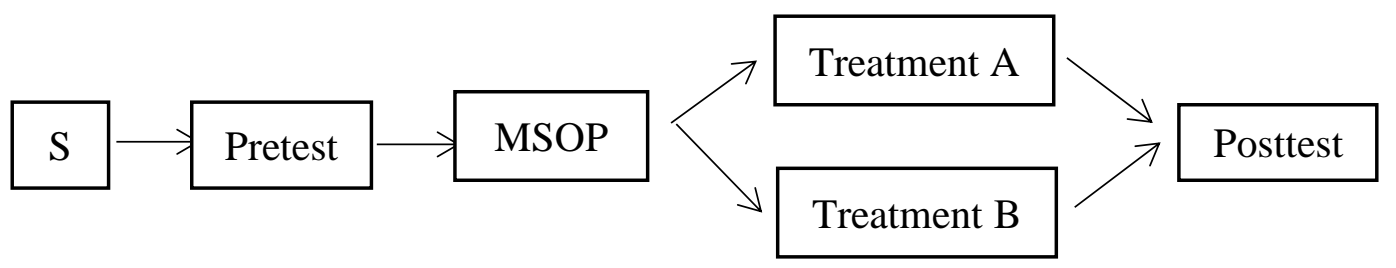

Gambar 1. One Group Pretest-Postest Design

(Sugiyono, 2007: 32)

Dalam penelitian ini menggunakan ordinal pairing yaitu dengan mengelompokan siswa berdasarkan hasil nilai dari poole forehand clear test yang telah di rangking, yaitu : 


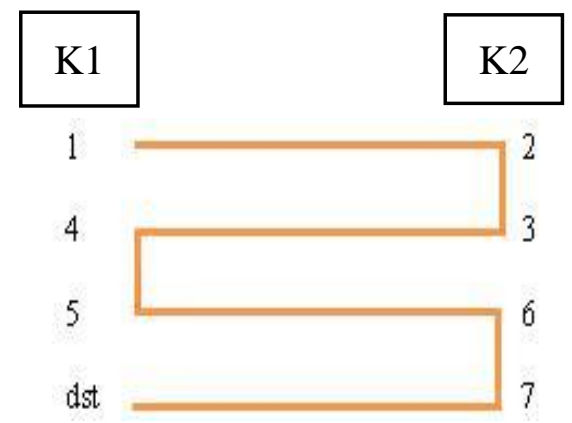

Gambar 2. Bagan ordinal pairing (Sutrisno Hadi, 1995: 485)

\section{HASIL PENELITIAN}

\section{Hasil Deskriptif Data Penelitian}

Hasil analisis deskriptif data penelitian dapat disajikan sebagai berikut:

\section{a. Pretest dan Posttest Ketepatan Jumping Smash Kelompok Plyometric}

\begin{tabular}{|l|l|c|c|c|}
\hline No & \multicolumn{1}{|c|}{ Nama } & Pre-Test & Post-Test & Peningkatan \\
\hline 1 & Aldi Pratama Putra & 34 & 36 & 2 \\
\hline 2 & Rafi Richard Abdullah & 34 & 35 & 1 \\
\hline 3 & Edvian Anindhito John & 33 & 34 & 1 \\
\hline 4 & Fais Reza Pamungkas & 33 & 35 & 2 \\
\hline 5 & Bayu Alvin Dwi Putra & 33 & 34 & 1 \\
\hline 6 & Aldian Tri Kuncoro & 32 & 33 & 1 \\
\hline 7 & Aditya Deyan Saputra & 32 & 34 & 2 \\
\hline 8 & Arjuna Enggi Jayanto & 31 & 32 & 1 \\
\hline 9 & Mikhael Gautama Alfa & 31 & 31 & 0 \\
\hline 10 & Nanda Okta Pradika & 30 & 31 & 2 \\
\hline
\end{tabular}

Tabel 1. Data Hasil Penelitian Kelompok Plyometric

Data yang dipaparkan di atas dianalisis menggunakan uji statistik sederhana, yaitu sebagai berikut:

\begin{tabular}{|l|l|c|c|}
\hline No & Jenis Penghitungan & Pre-test & Post-test \\
\hline 1 & Jumlah Total Nilai & 323 & 336 \\
\hline 2 & Banyaknya Atlet & 10 & 10 \\
\hline 3 & Nilai Terbesar & 34 & 36 \\
\hline 4 & Nilai Terkecil & 30 & 31 \\
\hline 5 & Mean & 32,3 & 33,6 \\
\hline 6 & Standar Deviasi & 1,337 & 1,577 \\
\hline
\end{tabular}


Tabel 2. Analisis Statistik Data Hasil Penelitian pada Plyometric

Hasil penelitian tersebut dideskripsikan menggunakan analisis statistik deskriptif untuk hasil pretest nilai minimal $=30$, nilai maksimal $=34$, rata-rata $=$ 32,3 , simpang baku $=1,337$, sedangkan untuk posttest nilai minimal $=31$, nilai maksimal $=36$, rata-rata $=33,6$, simpang baku $=1,577$.

\section{b. Pretest dan Posttest Ketepatan Jumping Smash Kelompok Circuit}

\begin{tabular}{|c|l|c|c|c|}
\hline No & \multicolumn{1}{|c|}{ Nama } & Pre-Test & Post-Test & Peningkatan \\
\hline 1 & Fathan Maulana & 34 & 34 & 0 \\
\hline 2 & Antonius Malvino Rheo & 34 & 35 & 1 \\
\hline 3 & Rahmat Puspita Bayu & 33 & 33 & 0 \\
\hline 4 & Bima Pramudya H & 33 & 33 & 0 \\
\hline 5 & Elnino Caesar Putra S & 32 & 33 & 1 \\
\hline 6 & Alvino Yanus Sakif & 32 & 32 & 0 \\
\hline 7 & Rasyad Shidqi L & 32 & 34 & 2 \\
\hline 8 & Hakam Genta Kusuma & 31 & 31 & 0 \\
\hline 9 & Maulana Adam G & 31 & 32 & 1 \\
\hline 10 & Rakha Yadika P & 31 & 32 & 1 \\
\hline
\end{tabular}

Tabel 3. Data Hasil Penelitian Kelompok Circuit

Data yang dipaparkan di atas dianalisis menggunakan uji statistik sederhana, yaitu sebagai berikut:

\begin{tabular}{|l|l|c|c|}
\hline No & Jenis Penghitungan & Pre-test & Post-test \\
\hline 1 & Jumlah Total Nilai & 323 & 329 \\
\hline 2 & Banyaknya Atlet & 10 & 10 \\
\hline 3 & Nilai Terbesar & 34 & 35 \\
\hline 4 & Nilai Terkecil & 31 & 31 \\
\hline 5 & Mean & 32,3 & 32,9 \\
\hline 7 & Standar Deviasi & 1,159 & 1,197 \\
\hline
\end{tabular}

Tabel 4. Analisis Statistik Data Hasil Penelitian pada

\section{Circuit}

Hasil penelitian tersebut dideskripsikan menggunakan analisis statistik deskriptif untuk hasil pretest nilai minimal $=31$, nilai maksimal $=34$, rata-rata $=$ 
32,3 , simpang baku $=1,159$, sedangkan untuk posttest nilai minimal $=31$, nilai maksimal $=35$, rata-rata $=32,9$, simpang baku $=1,197$.

\section{Uji Reliabilitas}

Hasil uji reliabilitas pre tes dan pos tes, test tersebut kemudian dikategorikan dengan menggunakan pedoman tabel koefisien korelasi dari book water yang dikutip dari Mulyono B. (1999:22). Dari kriteria tersebut berdasarkan hasil penelitian terhadap hasil uji dari data test awal - test akhir dalam penelitian ini yaiyu sebagai berikut.

\begin{tabular}{|c|c|c|}
\hline Hasil test & Reliabilitas & Kategori \\
\hline Tes Awal ( Pre-Test) & 0,84 & Tinggi \\
\hline
\end{tabular}

Tabel 5. Hasil Uji Reliabilias

\section{Pengujian Persyaratan Analisis}

Sebelum analisis data dilakukan uji persyaratan analisis. Untuk analisis regresi diperlukan uji persyaratan analisis yaitu normalitas penyebaran nilai dan persyaratan linieritas hubungan antara prediktor dengan kriterium. Hasil pengujian persyaratan analisis pada penelitian ini adalah sebagai berikut:

\section{a. Uji Normalitas}

Dalam penelitian ini, uji normalitas dilakukan menggunakan bantuan SPSS 23 dengan uji normalitas menggunakan kolmogrov-smirnov dengan taraf signifikan 5\%. Apabila diperoleh Asymp. Sig 5\%>0.05, maka data tersebut berdistribusi normal, namun apabila sebaliknya Asymp. Sig < 0.05 dapat disimpulkan bahwa data tersebut tidak normal.

\begin{tabular}{|l|l|c|c|l|}
\hline \multirow{2}{*}{ No } & \multirow{2}{*}{ Kelompok } & \multicolumn{2}{|c|}{$\begin{array}{c}\text { Kolmogrov- } \\
\text { Smirnov }\end{array}$} & \multirow{2}{*}{ Keterangan } \\
\cline { 3 - 5 } & $\begin{array}{c}\text { Sig. } \\
\text { Hitung }\end{array}$ & Sig. 5\% & \\
\hline 1 & $\begin{array}{l}\text { Pre-test } \\
\text { Plyometric }\end{array}$ & 0,200 & 0,05 & NORMAL \\
\hline 2 & $\begin{array}{l}\text { Post-test } \\
\text { Plyometric }\end{array}$ & 0,200 & 0,05 & NORMAL \\
\hline
\end{tabular}




\begin{tabular}{|l|l|l|l|l|}
\hline 3 & Pre-test Circuit & 0,200 & 0,05 & NORMAL \\
\hline 4 & Post-test Circuit & 0,200 & 0,05 & NORMAL \\
\hline
\end{tabular}

Table 7. Hasil Uji Normalitas

Dari keseluruhan data tersebut semuanya memiliki signifikansi hitung lebih besar dari 0.05 yang merupakan batas toleransi uji normalitas kolmogrov-smirnov pada taraf signifikansi 5\% dengan bantuan program SPSS 23, yaitu 0,200, 0,200, 0,200, 0,200 > 0.05. Maka dapat disimpulkan bahwa semua kelompok data yang ada dalam penelitian ini berdistribusi normal.

\section{b. Uji Homogenitas}

Dalam penelitian ini, uji homogenitas dalam penelitian ini menggunakan levene's test dengan taraf signifikan 5\% dengan bantuan program SPSS 23. Apabila taraf sig 5\%>0,05 maka data kedua kelompok tersebut memiliki kesamaan varian atau homogen, namun sebaliknya apabila taraf 5\%<0,05 maka data kedua kelompok tersebut tidak memiliki kesamaan varian atau tidak homogen.

\begin{tabular}{|l|l|c|c|c|}
\hline \multirow{2}{*}{ No } & \multirow{2}{*}{ Kelompok } & \multicolumn{2}{|c|}{ Kolmogrov-Smirnov } & \multirow{2}{*}{ Keterangan } \\
\cline { 3 - 4 } & & Sig. Hitung & Sig. 5\% & \\
\hline 1 & Pliometrik & 0,596 & \multirow{2}{*}{0,05} & HOMOGEN \\
\hline 2 & Circuit & 0,890 & HOMOGEN \\
\hline
\end{tabular}

Tabel 8. Hasil Uji Homogenitas

Kedua kelompok tersebut kesemuanya memiliki taraf signifikansi lebih besar dari 0.05 yang merupakan batas toleransi uji homogenitas levene's test pada taraf signifikan 5\% dengan bantuan program SPSS 23 yaitu, 0,596, 0,890>0,05. Maka dapat disimpulkan bahwa ketiga kelompok data tersebut homogen.

\section{Pengujian Hipotesis}

Hipotesis dalam penelitian ini diuji menggunakan paired $t$ test dan independent $t$ test dengan menggunakan bantuan SPSS 23, hasil uji hipotesis sebagai berikut:

\section{a. Perbandingan Pretest dan Posttest Ketepatan Jumping Smash Kelompok Plyometric dan Kelompok Circuit}


Kesimpulan penelitian dinyatakan signifikan jika nilai sig lebih kecil dari 0.05 $($ Sig $<0.05)$ dan $\mathrm{t}$ hitung $>$ tabel. Jika sig $>0.05$ dan $\mathrm{t}$ hitung $<\mathrm{t}$ tabel penelitian dinyatakan tidak ada pengaruh yang signifikan. Berdasarkan hasil analisis diperoleh data sebagai berikut.

\begin{tabular}{|c|c|c|c|c|c|c|c|}
\hline \multirow[b]{2}{*}{ Kelompok } & \multirow{2}{*}{$\begin{array}{l}\text { Rata- } \\
\text { Rata }\end{array}$} & \multicolumn{5}{|c|}{ t-test for Equality of means } & \multirow[b]{2}{*}{ Ket } \\
\hline & & Selisih & t hit & $\begin{array}{c}\mathbf{t} \\
\text { table }\end{array}$ & $\begin{array}{l}\text { Sig. } \\
\text { hit }\end{array}$ & $\begin{array}{l}\text { Sig } \\
\mathbf{5 \%}\end{array}$ & \\
\hline PreTest Plyometric & 32,30 & \multirow{2}{*}{1,30} & \multirow{2}{*}{6,091} & \multirow{2}{*}{2,262} & \multirow{2}{*}{0,00} & \multirow{2}{*}{0,05} & \multirow{2}{*}{ Signifikan } \\
\hline PostTest Plyometric & 33,60 & & & & & & \\
\hline PreTest Circuit & 32,30 & \multirow{2}{*}{0,60} & \multirow{2}{*}{2,714} & \multirow{2}{*}{2,262} & \multirow{2}{*}{0,024} & \multirow{2}{*}{0,05} & \multirow[t]{2}{*}{ Signifikan } \\
\hline PostTest Circuit & 32,90 & & & & & & \\
\hline
\end{tabular}

Tabel 9. Uji-t Hasil Pre-Test dan Post-Test Ketepatan Jumping Smash Kelompok Plyometric dan Kelompok Circuit

Dari hasil uji-t kelompok plyometric dapat dilihat bahwa nilai signifikansi $\mathrm{p}$ sebesar $0,000<0.05$ dan nilai thitung 6,091 > t table 2,262 dengan selisih nilai ratarata 1,30. Dan hasil uji-t kelompok circuit dapat dilihat bahwa nilai signifikansi $\mathrm{p}$ sebesar $0,024<0.05$ dan nilai $\mathrm{t}$ hitung 2,714 > t table 2,262 dengan selisih nilai ratarata 0,60 . Dengan demikian hipotesis alternatif $(\mathrm{Ha})$ yang berbunyi "Ada perbedaan pengaruh yang signifikan pada latihan plyometric dan latihan circuit terhadap ketepatan jumping smash bulutangkis pada atlet remaja di PB Independent Karanganyar" DITERIMA.

\section{b. Perbandingan Posttest Ketepatan Jumping Smash Kelompok Plyometric dengan Kelompok Circuit}

Kesimpulan penelitian dinyatakan jika nilai t hitung $>\mathrm{t}$ tabel dan jika nilai sig lebih kecil dari 0.05 (Sig < 0.05). Berdasarkan hasil analisis diperoleh data sebagai berikut. Berdasarkan hasil analisis diperoleh data sebagai berikut.

\begin{tabular}{|l|l|c|c|c|c|c|c|}
\hline \multirow{2}{*}{ Kelompok } & \multirow{2}{*}{$\begin{array}{l}\text { Rata- } \\
\text { Rata }\end{array}$} & Selisih & t hit & t table & Sig. hit & $\begin{array}{c}\text { Sig } \\
\mathbf{5 \%}\end{array}$ & \multirow{2}{*}{ Ket } \\
\cline { 2 - 8 } & & & & & & \\
\hline Pliometrik & 33,60 & 0,70 & 2,333 & 2,262 & 0,045 & 0,05 & Signifikan \\
\hline
\end{tabular}




\section{\begin{tabular}{|l|r|}
\hline Circuit & 32,90 \\
\hline
\end{tabular}}

Tabel 10. Uji t Kelompok Plyometric dengan Kelompok Circuit

Dari hasil uji-t dapat dilihat bahwa t hitung 2,333 > t tabel 2,262 dengan nilai signifikansi $\mathrm{p}>0,045$. Berdasarkan hasil analisis diperoleh nilai rerata selisih peningkatan sebesar 0,70. Dengan demikian menunjukkan bahwa "Latihan plyometric terdapat pengaruh yang lebih signifikan daripada lathan circuit terhadap hasil peningkatan kemampuan jumping smash pada atlet remaja di PB Independent Karanganyar". DITERIMA.

\section{c. Perbandingan Kenaikan Persentase Kelompok Plyometric dan Kelompok Circuit}

Dapat diketahui peningkatan persentase melalui selisih mean antara kelompok Plyomeric dengan kelompok Circuit. Berdasarkan hasil analisis diperoleh data sebagai berikut.

\begin{tabular}{|l|c|c|}
\hline \multicolumn{1}{|c|}{ Kelompok } & Selisih & Kenaikan \% \\
\hline PreTest - PostTest Plyometric & 1,30 & $4 \%$ \\
\hline PreTest - PostTest Circuit & 0,60 & $2 \%$ \\
\hline PostTest Plyometrik - PostTest Circuit & 0,70 & $2 \%$ \\
\hline
\end{tabular}

Tabel 11. Perbandingan Kenaikan Persentase Persentase Kelompok Plyometric dan Kelompok Circuit

Berdasarkan hasil analisis diperoleh nilai rerata selisih postest kelompok latihan plyometric sebesar 1,30, nilai rerata posttest kelompok latihan circuit sebesar 0,60, dilihat dari selisih nilai posttest sebesar 0,70. Artinya latihan plyometric lebih berpengaruh disbanding latihan circuit terhadap peningkatan ketepatan jumping smash atlet bulutangkis PB Independen Karanganyar Tahun 2020.

\section{A. Pembahasan Hasil Analisis Data}

\section{a. Perbandingan Pretest dan Posttest Ketepatan Jumping Smash Kelompok Plyometric dan Kelompok Circuit}

Pada hasil analisis data menunjukan bahwa latihan plyometric t hitung 6,091

$>\mathrm{t}$ tabel 2,262 dan nilai signifikansi $0,000<0,05$. Dan juga hasil analisis data 
menunjukkan bahwa latihan circuit t hitung 2,714>t tabel 2,262 dan nilai signifikansi $0,024<0,05$. Dengan demikian hipotesis alternatif $(\mathrm{Ha})$ yang berbunyi "Ada perbedaan pengaruh yang signifikan latihan plyometric dan latihan circuit terhadap peningkatan kemampuan jumping smash bulutangkis pada atlet remaja di PB Independent Karanganyar” diterima.

Dari data kelompok Plyometric mean pretest 32,30, dan pada saat posttest mean mencapai 33,60. Besarnya peningkatan mean ketepatan jumping smash kelompok plyometric yaitu sebesar 1,30. Sedangkan pada kelompok circuit memiliki mean pretest 32,30, dan pada saat posttest mean mencapai 32,90. Besarnya peningkatan mean ketepatan jumping smash tersebut dapat dilihat dari perbedaan nilai rata-rata yaitu sebesar 0,60 .

\section{b. Perbandingan Posttest Ketepatan Jumping Smash Kelompok Plyometric dengan Kelompok Circuit}

Dari hasil uji-t dapat dilihat bahwa t hitung 2,333 > t tabel 2,262 dan nilai signifikansi $0,045<0,05$. Maka hasil ini menunjukkan terdapat perbedaan yang signifikan. berarti ada perbedaan yang signifikan antara posttest kelompok latihan plyometric dengan posttest kelompok latihan circuit.

Berdasarkan hasil analisis diperoleh nilai rerata selisih postest kelompok latihan plyometric sebesar 33,60, nilai rerata posttest kelompok latihan circuit sebesar 32,90, dilihat dari selisih nilai posttest sebesar 0,70. Dengan demikian menunjukkan bahwa "Latihan plyometric terdapat pengaruh yang lebih signifikan daripada latihan circuit terhadap hasil peningkatan kemampuan jumping smash pada atlet remaja di PB Independent Karanganyar” diterima.

\section{KESIMPULAN}

Berdasarkan hasil analisis data, deskripsi, pengujian hasil penelitian, dan pembahasan, dapat diambil kesimpulan bahwa: 
1. Ada perbedaan pengaruh yang signifikan antara latihan plyometric dan latihan circuit terhadap peningkatan ketepatan jumping smash atlet bulutangkis PB Independen Karanganyar. Dengan t hitung 2,333 > t table 2,262 dan nilai signifikansi p $0,045<0,05$.

2. Latihan plyometric memberikan pengaruh lebih signifikan daripada latihan circuit terhadap peningkatan ketepatan jumping smash atlet bulutangkis PB Independen Karanganyar. Dengan selisih mean peningkatan 0,70 dan selisih peningkatan persentase sebesar $2 \%$.

\section{DAFTAR PUSTAKA}

Purnama. 2010. Kepelatihan bulutangkis modern. Surakarta: Yuma Pustaka.

Radiclife, J.C \& Farentinous, R.C. 2002. Power training for sport, plyometrics for maximum power development. Canada: Coaching Association of Canada.

Ria Lumintuarso. 2011. Peralatan Olahraga Anak FOA. Jogjakarta: PKO FIK.

Rusli Lutan. 2013. Tahir Djide Hidup dan Karyanya dalam Bulutangkis. Jakarta: Departemen Pendidikan dan Kebudayaan.

Sugiyono. 2006. Statistik untuk Penelitian. Bandung: Alfabet.

Sutrisno Hadi. 2015. Statistika. Yogyakarta: Pustaka Pelajar

Syahri Alhusin. 2007. Gemar Bermain Bulutangkis. Surakarta : CV Seti-Aji

Tohar. 1992. Olahraga pilihan bulutangkis. Semarang: IKIP Semarang.

Weinberg, Robert S and Gould, Daniel. 2003. Foundations of sport and exercise psychology, $3^{\text {rd }}$ edition. Champaign, II. United States of America: Human Kinetics. 